\title{
THE IMPACT OF PROGRESSIVE GEAR GEOMETRY ON THE BRAKING DISTANCE LENGTH UNDER CHANGEABLE OPERATING CONDITIONS
}

\author{
Paweł Lonkwic ${ }^{1}$, Kamil Szydło², Szymon Molski ${ }^{3}$ \\ 1 Lublin Factory of Passenger Lifts 'Lift Serivce' S.A. Roztocze Str. 6, 20-722 Lublin, Poland, e-mail: plonkwic@ \\ gmail.com \\ 2 Lublin University of Technology, Mechanical Engineering Faculty, Department of Motor Vehicles, Nad- \\ bystrzycka Str. 36, 20-722 Lublin, Poland, e-mail: kamil-szydlo@wp.pl \\ 3 AGH University of Science and Technology, Faculty of Mechanical Engineering and Robotics, Department of \\ Rope Transport, Mickiewicza Str. 30, 30-059 Kraków, Poland, e-mail: molski@agh.edu.pl
}

Received: 2015.12 .15

Accepted: 2016.02.01

Published: 2016.03.01

\begin{abstract}
This article presents independent tests results focused on the geometry impact of progressive gear used in a short distance transportation devices on the braking distance length both under changeable operating conditions as well as changeable loading. Variable operating conditions were obtained with the use of various lubricating agents. Five types of gears such as ASG100, PP16, PR2000, KB160 and a new solution CHP2000 were used for the tests. The tests were conducted with a free fall method application. The method gave a chance to evaluate reliability of tested gears systems and to compare the existing solutions with the proposed gear of CHP2000 type.
\end{abstract}

Keywords: safety gears, reliability, traction lift, braking.

\section{INTRODUCTION}

The issues connected with the operation of lifting devices under changeable conditions of forces and displacements, taking into account the influence of operating phenomena on the structure resistance aspects and the application of numerical techniques in virtual prototyping of the structure elements, are quite widely described in the literature. In the standard [8] a sliding gear is defined as a device where delay is generated by braking on the guides and where special means are undertaken to limit, up to the acceptable value, the force put on the cabin, the counterweight or balancing mass. In other words, the sliding gear is nothing more than a form of a break protecting the lift from uncontrolled speeding. The aspects connected with the use of Finite Element Method (FEM) to evaluate the stiffness and resistance of the cabin frames construction in different types of lifts, including also different types of gears, are presented in the publication [1]. FEM was used in the above mentioned topics to optimize the carrying frame of the construction. It refers to the reduction of cross sections in the frame construction beams, reduction of its weight and identification of safety coefficients. On the basis of received results they tried to identify those places of the lift frame system which are sensitive to the presence of damage in the construction knots possessing the gears. The delay analyses results, progressive gears braking forces and a distance taken by the system under tests in the situation of emergency braking are presented in the publication [3]. The tests were performed with a free fall method for the values of speed higher than $1.6 \mathrm{~m} / \mathrm{s}$. The tests were connected with the method aiming at specifying a series of braking parameters of the gears system as well as connected with the operating aspects of the entire lift braking system.

Finite element method was used [4] to determine the value of stresses and displacements of the braking system in a hydraulic lift. The authors compare the results of numerical analysis with 
the results of an experiment. The results obtained via the experiment in the authors' opinion gave the output convergent to this received via simulation. The authors of the publication [2] are engaged in the aspects of the ,reduction" method in order to assess the lift operation. The model of the lift cabin was reduced to the flat system with one, vertical level of freedom in the presented analyses. The displayed methodology of reduction was used by the authors to describe a specific mechanism of a cargo lift depicting the presented subjects in a mathematical way.

Nowadays, the FEM is widely used to model the phenomena taking place when not only metal elements cooperate. FEM aspects are used [5] to model the phenomena appearing under operating dependencies of the elements produced with different manufacturing methods and made of high density polyethylene.

The aspects connected with dynamics of the lift braking system, the analysis of applied materials and the gears were touched in the research studies $[6,7]$. The authors in their publications, among others, pay their attention to the analysis of braking system. They compare the construction and operation of the gears produced by European manufacturers with newly-developed solution such as CHP 2000 type progressive gears. The authors analyse correctness of the designed gear construction with the use of FEM numerical analysis and they compare the developed construction with the existing solutions. The aspects connected with the application of neural networks to analyse vibrations of working lift due to changeable mass of transported load are presented in the research study [10]. The applied neural networks were used to evaluate the vibrations symptoms as a consequence of which it would be possible to identify damage of some part of the lift or the whole device. In publication [9] the authors touch the aspects connected with the mass influence of the wires supplying the lift cabin with power and the carrying ropes, in the so called tall lifts working in tall buildings over 40 floors, on its work. In this type of lifts, significant height of lifting is connected with the fact that it is needed to use a leveling belt to compensate the carrying ropes and power supply wires weight due to which the remaining subassys of the lift are not excessively loaded. The authors in a model way describe the behaviour of the leveling belt and its influence on the linear model of the lift operation. They also analyse the impact of horizontal displacements of a leveling belt on the frequencies of individual system vibrations.

While analysing the literature it can be stated that clear research studies containing simulation tests results regarding the operation of the progressive gears under changeable conditions are missing. With respect to the above, it is justifiable to conduct further research tests on the impact of changeable loading and changeable operating conditions on the braking process of progressive gears.

\section{CHARACTERISTIC OF TESTED GEARS}

The progressive gears are characterized with progressive features of braking where the speed of coasted mass is reduced along a significant distance dependent not only on the gear construction but also on the conditions under which the braking process takes place. The gears constructions subject to the tests are presented in Figures 1-5.

The tests were conducted by the simulation of a free fall of the friction lift as a consequence broken off carrying ties. The test bench, the scheme of which is presented in Figure 6, was built for testing purposes. The guides were installed in the test bench construction. The frame loading the gears was going along the guides. The system controlling the speed of free fall was joined to the frame with the gears. The system task was to initiate the braking process once the nominal speed was exceeded by $0.3 \mathrm{~m} / \mathrm{s}$. Measurement of the braking parameters was recorded by a sensor which was joined with PC class computer. Once the free fall

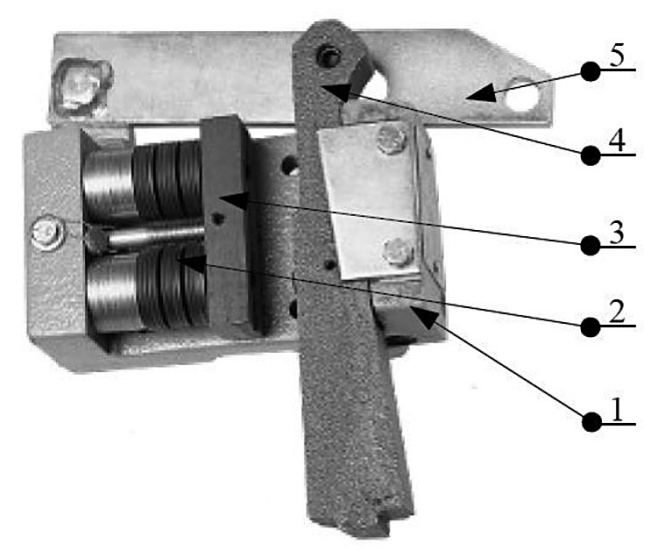

Fig. 1. Diagram of progressive safety gears of type KB160: 1 - a frame, 2 - belleville springs, 3 - a lever, 4 - a screw limiting the wedge stroke, 5 - the gear mounting mechanism [7] 


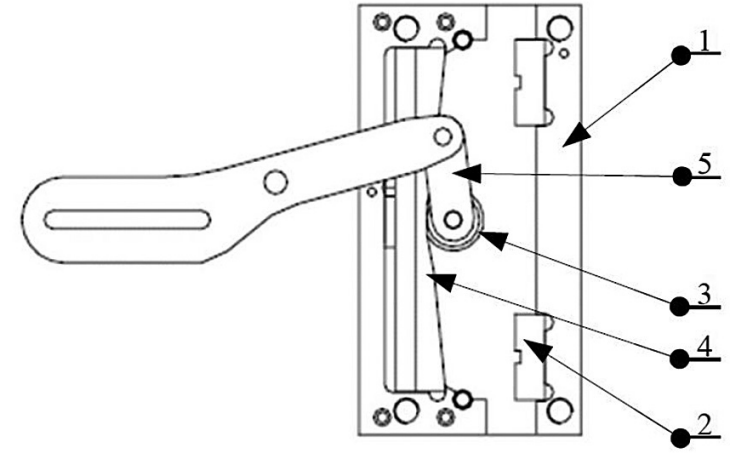

Fig. 2. Diagram of progressive safety gears of type ASG100: Diagram of progressive safety gears of ASG100 type: 1 - a frame, 2 - a blocking roller, 3 - a clamping spring, 4 - a lever [7]

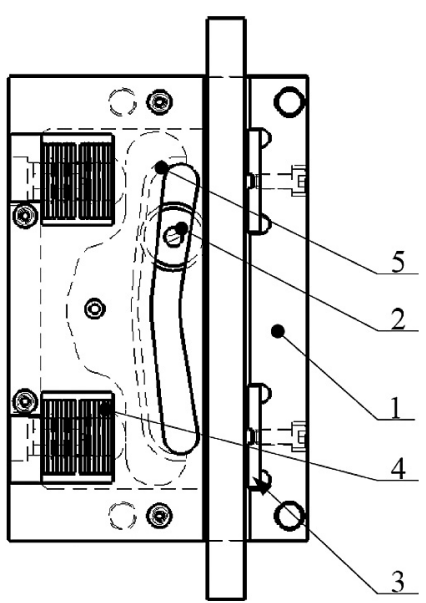

Fig. 4. Diagram of progressive safety gears of type CHP2000: 1 - a frame, 2 - a braking plate, 3 - a clamping roller, 4 - a wedge, 5 - a lever [7]

started, the gear lever hit the clamp of a speed limiter rope and initiated the braking process. The height of the free fall at which the frame system had to be lifted was determined on the basis of empirical dependencies of potential and kinetic energy. The free fall height was calculated as described above and presented with the use of dependence (1).

$$
h=\frac{v_{1}^{2}}{2 \cdot g}+0.1+0.03
$$

where: $h$ - height of the free fall [m],

$v_{1}-$ speed to release the gears, for research studies $1,25[\mathrm{~m} / \mathrm{s}]$ value was accepted,

$g-$ acceleration of gravity $-9,81\left[\mathrm{~m} / \mathrm{s}^{2}\right]$,

0.1 - coefficient of delay in the gears start up [-],

0.03 - coefficient of excessive clearances

in the braking system [-].

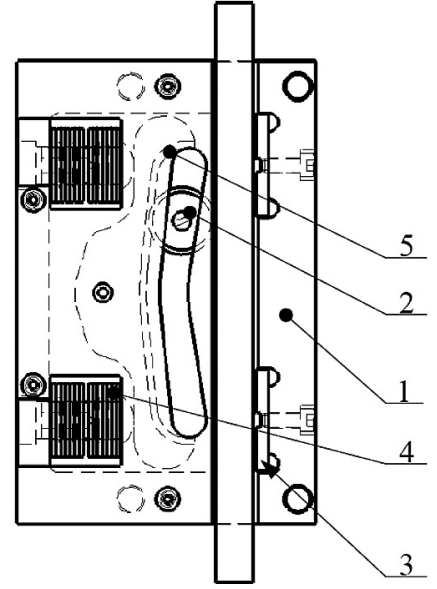

Fig. 3. Diagram of progressive safety gears of type PR2000UD: 1 - a frame, 2 - a braking plate, 3 - a clamping roller, 4 - a wedge, 5 - a lever [7]

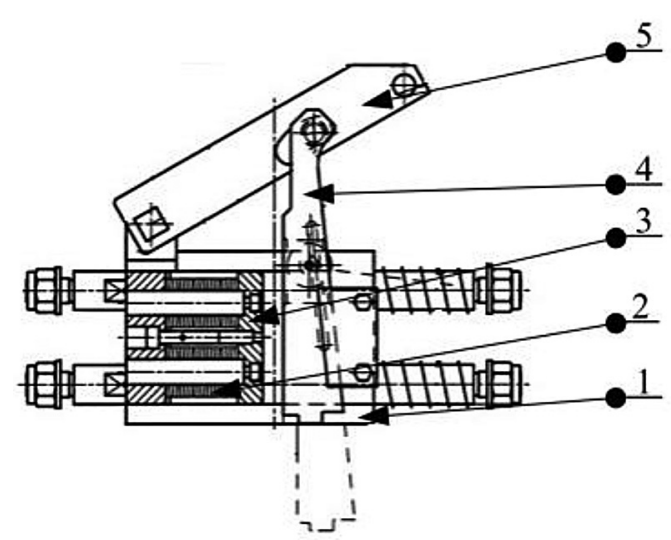

Fig. 5. Diagram of progressive safety gears of PP16 type: 1 - a frame, 2 - belleville springs, 3 - a braking plate, $4-$ a wedge, 5 - a lever [7]

Measuring equipment and software developed for the tests described in this research study were used to measure accelerations and the braking distance. All four measuring tracks were attached to the measuring card - LABVIEW 9215 which was joined with PC class computer where registered data was recorded.

\section{EXPERIMENT}

Tests of the braking process were conducted under the conditions without lubrication of the guides system as well as with the use of two types of lubricating agents and their mixtures. Under operating conditions that give different levels of the guides contamination, along which the gears move. Identifications of respective conditions of the guides prepared for tests are described with 


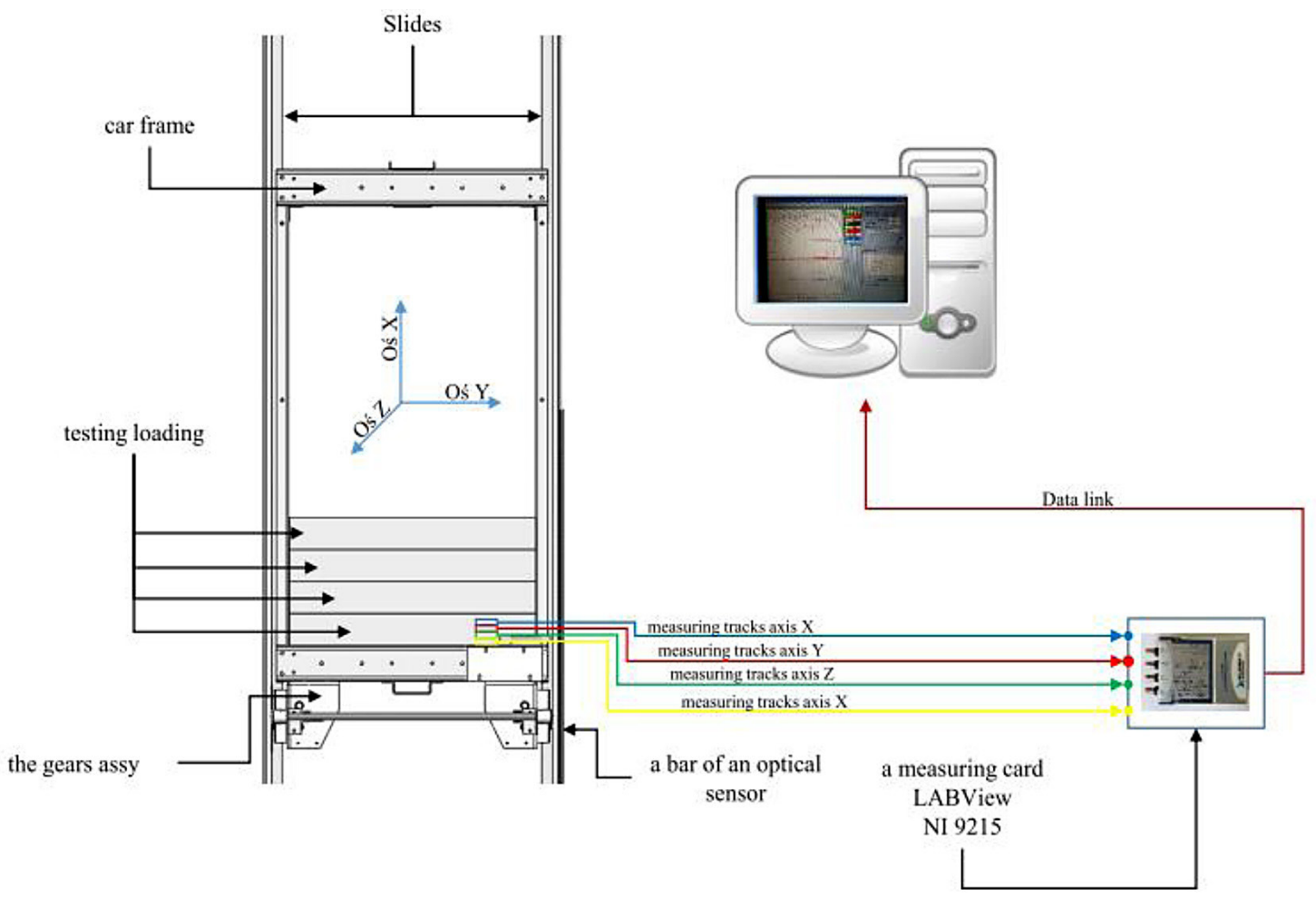

Fig. 6. Scheme of a test bench

the codes as in the below scheme:

- tests under dry conditions without lubricating agent, identified in the plan as ,dry operation';

- tests under conditions lubricated with RENOLIN B20 oil identified in the plan as "mineral oil";

- tests under conditions lubricated with ŁT-43 grease as per ISO 6743-9 RENOLIN B20, identified in the plan as ,solid grease";

- tests under conditions lubricated with the mixture of RENOLIN B20 oil and quartz sand in the proportion of 50/50, identified in the plan as „O50B”;

- tests under conditions lubricated with the mixture of $\mathrm{LT}-43$ grease and quartz sand in the proportion of $50 / 50$, identified in the plan as „S50B”.

Selected physicochemical properties of the applied lubricating agents are presented in Table 1. Example of tests plan scheme is presented in Figure 7. Measurements for all five types of the gears were conducted in accordance with the plan.

\section{RESULTS OF SELECTED SIMULATIONS}

The experimental tests were conducted under laboratory conditions reflecting device function-
Table 1. Selected physicochemical properties of applied lubricating agents

\begin{tabular}{|l|c|}
\hline \multicolumn{1}{|c|}{ Specification } & Scope \\
\hline \multicolumn{2}{|c|}{ Renolin B20 OIL } \\
\hline State of matter & liquid \\
\hline Colour & brown \\
\hline Kinematic viscosity, cSt & 68 \\
\hline Relative density at $15^{\circ} \mathrm{C}, \mathrm{g} / \mathrm{cm}^{3}$ & 0.88 \\
\hline Flashpoint, ${ }^{\circ} \mathrm{C}$ & 218 \\
\hline \multicolumn{2}{|c|}{$\mathrm{kT} \mathbf{4 3}$ GREASE } \\
\hline State of matter & solid substance \\
\hline Colour & green \\
\hline Kinematic viscosity, $\mathrm{cSt}$ & 90 \\
\hline Relative density at $15^{\circ} \mathrm{C}, \mathrm{g} / \mathrm{cm}^{3}$ & 1 \\
\hline Flashpoint, ${ }^{\circ} \mathrm{C}$ & 200 \\
\hline
\end{tabular}

ality status. The free fall in the considered cases simulated the operation in real conditions when all carrying ties of the lift break off. As a consequence of conducted tests the following results were obtained for emergency braking of the tested system (Figures 8, 9, 10).

The impact of respective types of gears loading on the value of braking distance depending on different operating conditions is presented in Figure 8a to 8e. KB160, PR 2000 


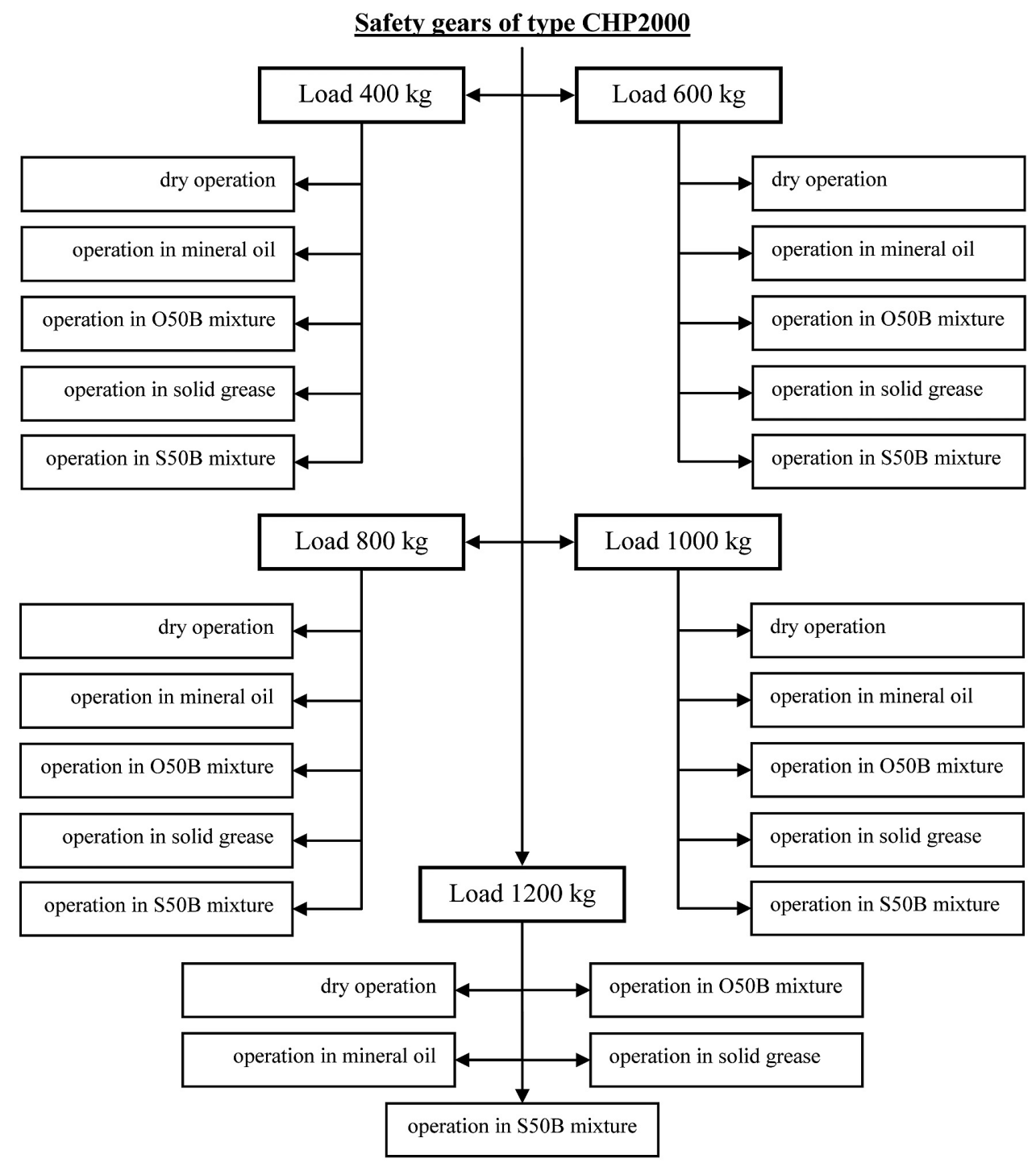

Fig. 7. Plan of experimental tests for one type of the gear

and ASG160 gears, in a range of loadings subject to tests, demonstrated the most consistent characteristic of braking (differences between estimated values are the lowest). The gears of PP16 type behaved in an opposite way, where due to their geometry and kinematics of operation, the differences in respective values are the largest. CHP 2000 gears for the value of loading from 400 to 1000 demonstrated coherent characteristic of braking, whereas for the value of loading equal to 1200 the braking distance deviated from the remaining four ones. Thus, it can be assumed that together with the rise of loading, the gears CHP 2000 increase their braking distance, having a positive impact also on the operating or durability factors. A comparison of the gears in terms of their operation depending on the loading and also under changeable conditions is presented in Figure 9a to 9e. All types of the tested gears proved that, under the conditions of „S” dry operation, regardless of the applied loading, the value of braking distance is the shortest one. Extended braking distance was observed after the application of „OL" mineral oil and „SM" solid grease. The application of oil, grease and quartz sand mixture disturbed the braking process but it did not eliminate it. It can be presumed that when the guides are covered with a lubricating agent with addition of sand, then in some cases, the value of braking distance is reduced. $12000 \mathrm{~N}$ loading put on PP16 gears resulted in improper braking of the gears. It is described in the drawings with " 0 " values and omitted in the received analyses. In most cases the gears of CHP 2000 type reached the highest values of braking distance what led to the gentlest stoppage of speeding mass in reality. 
a)

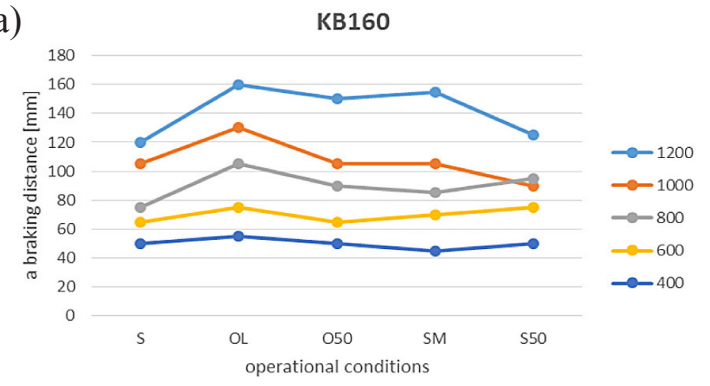

c)

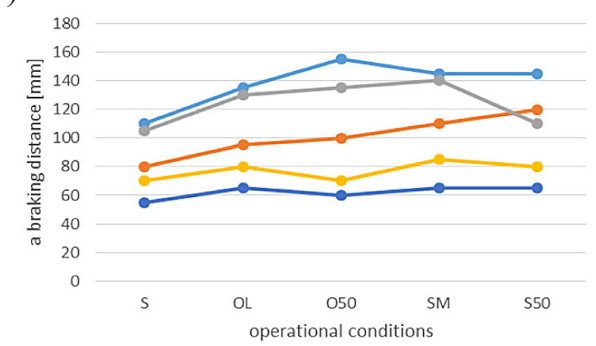

e) b)

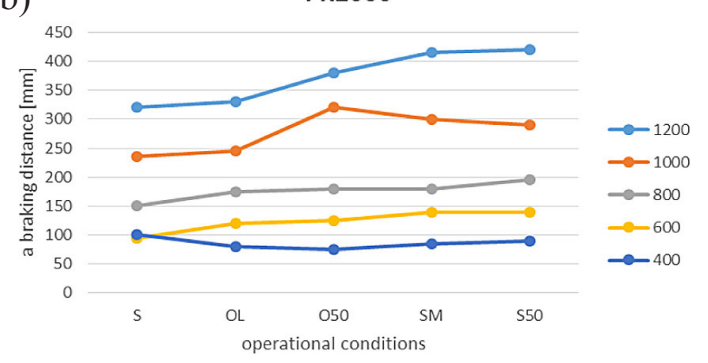

d)

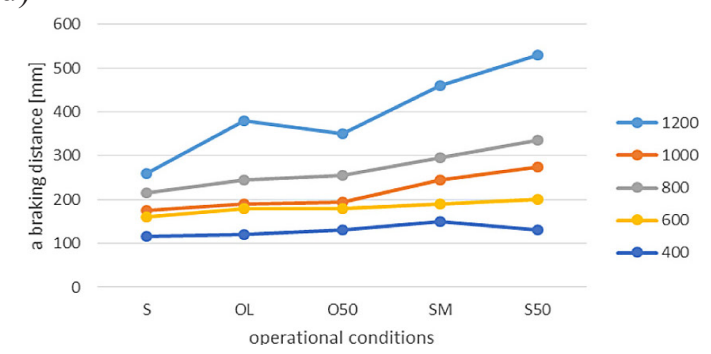

PP16

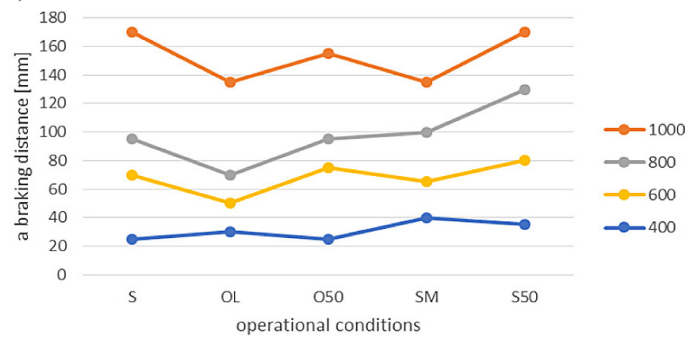

Fig. 8. Influence of the gear loading on the value of braking distance length

a)

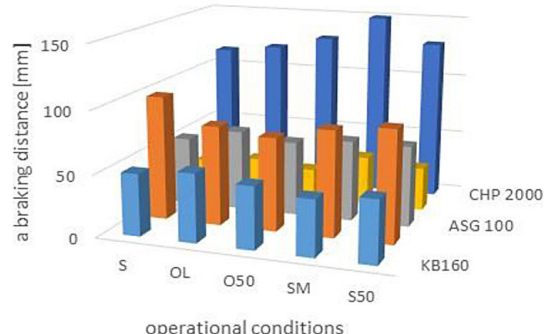

c)

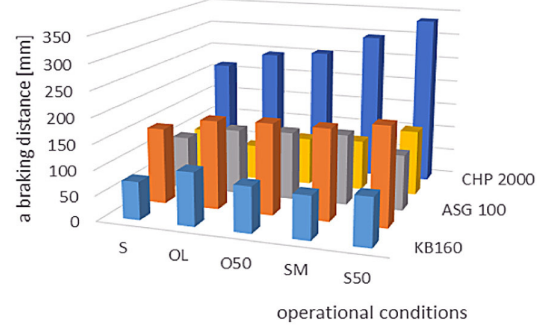

e) b) Loading capacity $6000 \mathrm{~N}$

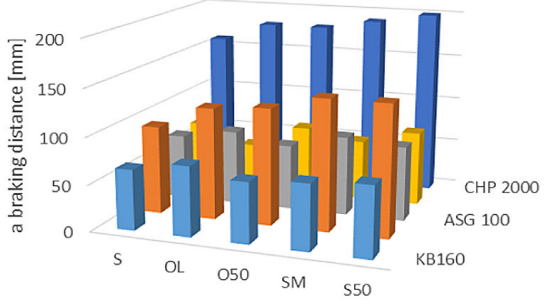

operational conditions

d)
- KB160

- $\mathrm{PR} 2000$

$\square$ ASG 100

- PP16

- CHP 2000

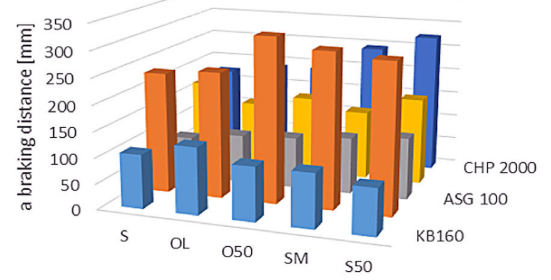

घBB160 - $\mathrm{PR} 2000$ - ASG 100 푸 16 - CHP 2000

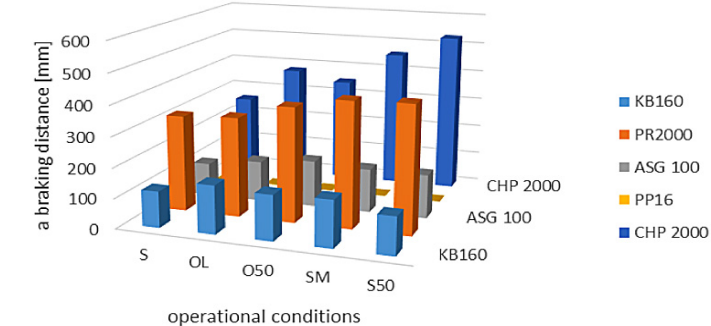

Fig. 9. Influence of the gear construction on the length of braking distance under changeable operating conditions 


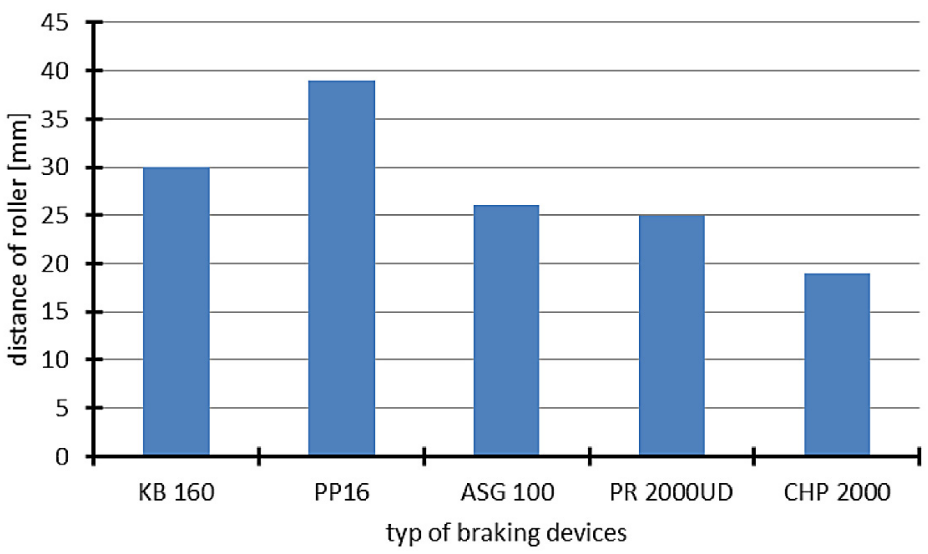

Fig. 10. Influence of the gear construction on the effective braking distance [7]

\section{CONCLUSIONS}

The complexity of the phenomena accompanying the braking process, in other words, the condition of the guides cleanliness or the quality of applied grease, not always give a chance to identify the process fully. Then, an effort is made to identify a physical model via the observation on the basis of simulation and laboratory tests. The authors of the article, while conducting the tests on the application of lubricating agents, possessed data within their physicochemical properties but did not take them into account in the tests. The focus was put only on the application of lubricating agents as the means to disturb the braking process. Mixtures of lubricating agents were prepared by joining them with quartz sand what in effect simulated the operating contamination of the guides under real surroundings conditions. It was attempted to correlate the gear geometry with the length of braking distance depending on the loading and conditions of the gear operation. As proved by the tests, the gears of KB 160, PR2000, ASG100 and PP 16 type possess the longest free movement of the gear roll, as a consequence of that, their braking distance is shorter but the value of braking process delay is increased. The gears of CHP 2000 type acquire in their construction the shortest free movement of the roll. It means that their braking distance is the longest one and as a consequence the value of braking delay is reduced (Figure 10). This behavior gives the possibility to think that operation life of the roll (without its permanent damage) would be extended in relation to the existing solutions. The applied construction of CHP 2000 gear allows to conduct further tests in this field of study. Further research regarding the operation of progressive gears should focus.

\section{REFERENCES}

1. Feng L., Bao Y., Zhou X., Wang Y. High speed elevator car frame's finite elements analysis. Advanced Materials Research 510, 2012, 298-303.

2. Filas J., Mudro M. The dynamic equation of motion of driving mechanism of a freight elevator. Procedia Engineering 48, 2012, 149-152.

3. Jong de J. Understanding the natural behavior of elevator safety gears and their triggering. The International Congress on Vertical transportation technologies, Istambul 2004.

4. Kayaoglu E., Salman O., Candas A. Study on stress and deformation of an elevator safety gear brake block using experimental and FEA methods. Advanced Materials Research 308-310, 2011, 1513-1518.

5. Klepka T., Dębski H., Rydarowski H. Characteristic of high-density polyethylene and its properties simulation with use of finite element method. Polimery 54(9), 2009, 668-672.

6. Lonkwic P, Różyło P, Dębski H. Numerical and experimental analysis of the progressive gear body with the use of finite-element method. Maintenance and Reliability 17(4), 2015, 542-548, http:// dx.doi.org/10.17531/ein.2015.4.9

7. Lonkwic P. Influence of friction drive lift gears construction on the length of braking distance. Chinese Journal of Mechanical Engineering 28(2), 2015, 363-368.

8. Polska Norma PNEN 81-1 Przepisy bezpieczeństwa dotyczące budowy i instalowania dźwigów. Cz. 1. Dźwigi elektryczne 2002.

9. Onur Y.A., Imrak C.E. Reliability analysis of elevator car frame using analytical and finite element methods. Building Services Engineering Research \& Technology 33(3), 2012, 293-305.

10. Taplak H., Erkaya S., Yildirim S., Uzmay I. The use of neural network predictors for analyzing the elevator vibrations. Mechanical Engineering 39, 2014, 1157-1170. 